\title{
Bisphosphonate drug holidays
}

\section{S. Nayak ${ }^{1}$ - S.L. Greenspan ${ }^{2}$}

Received: 27 June 2019 / Accepted: 21 July 2019/Published online: 15 October 2019

(C) International Osteoporosis Foundation and National Osteoporosis Foundation 2019

Dear Editor,

We appreciate Dr. Anagnostis and colleagues' thoughtful comments on our recent study [1]. We agree that our findings are generally in accordance with Anagnostis et al.'s systematic review performed to inform a position statement of the European Menopause and Andropause Society (EMAS) in 2017 [2]. With respect to the evidence for risedronate, although there is a study that has shown that after 3 years of prior risedronate treatment, discontinuation of treatment for 1 year resulted in retained reduced incidence of new morphometric vertebral fractures in the former risedronate group compared with the former placebo group [3]; we are not aware of any study that has compared fracture risk in individuals who continued on risedronate treatment beyond 3 years with individuals who received treatment for at least 3 years and subsequently discontinued. Thus, evidence is still lacking to inform whether there is benefit to continuing risedronate beyond 3 years compared with taking a drug holiday after 3 years of risedronate treatment. We agree with Anagnostis et al.'s point that there was significant heterogeneity between the cohort studies included in the meta-analyses we performed, and that the null results for the impact of bisphosphonate discontinuation on risk of hip fracture or any clinical fracture do not necessarily apply to all patients with osteoporosis. Finally, we agree with Dr. Anagstosis and colleagues' assertion that given the current evidence base, bisphosphonate discontinuation decisions should be individualized.

\section{Compliance with ethical standards}

Conflict of interest Smita Nayak declares no conflict of interest. Susan L. Greenspan receives research funding from Amgen and Radius.

\section{References}

1. Nayak S, Greenspan SL (2019) A systematic review and metaanalysis of the effect of bisphosphonate drug holidays on bone mineral density and osteoporotic fracture risk. Osteoporos Int 30:705720

2. Anagnostis P, Paschou SA, Mintziori G, Ceausu I, Depypere H, Lambrinoudaki I, Mueck A, Pérez-López FR, Rees M, Senturk LM, Simoncini T, Stevenson JC, Stute P, Trémollieres FA, Goulis DG (2017) Drug holidays from bisphosphonates and denosumab in postmenopausal osteoporosis: EMAS position statement. Maturitas 101:23-30

3. Watts NB, Chines A, Olszynski WP, McKeever CD, McClung MR, Zhou X, Grauer A (2008) Fracture risk remains reduced one year after discontinuation of risedronate. Osteoporos Int 19:365-372

Publisher's note Springer Nature remains neutral with regard to jurisdictional claims in published maps and institutional affiliations.
S. Nayak

smita.nayak@berkeleymadonna.com

1 Berkeley Madonna, Inc., 1135 Spruce St., Berkeley, CA 94707-2629, USA

2 University of Pittsburgh School of Medicine, Pittsburgh, PA, USA 